\title{
DA LIBERTAÇÃO À HEGEMONIA: FREIRE E GRAMSCI NO PROCESSO DE DEMOCRATIZAÇÃO DO BRASIL
}

\author{
Giovanni Semeraro
}

\begin{abstract}
RESUMO
As lutas populares que se desencadearam no Brasil desde os anos 1960 até hoje podem ser caracterizadas por dois grandes paradigmas: "libertação" e "hegemonia". A "libertação" foi a tônica predominante nos anos 1960 e 1970. A "hegemonia" tem sido a palavra de ordem ao longo dos anos 1980 e 1990. A primeira, representada particularmente por Paulo Freire, e a segunda, tendo em Antonio Gramsci sua referência maior, foram se entrelaçando e tornaram-se inseparáveis no desenho de um projeto alternativo de sociedade. Neste artigo, apresenta-se uma análise crítica de seus significados em decorrência dos dez anos da morte de Paulo Freire e dos 70 da morte de Gramsci. O texto que segue, além de percorrer os significados, as diferenças e o entrelaçamento de "libertação" e "hegemonia" em seu contexto histórico e social, apresenta uma reinterpretação dos dois paradigmas ante as mudanças políticas e culturais atualmente em curso no Brasil e na América Latina.
\end{abstract}

PALAVRAS-CHAVE: hegemonia; libertação; política.

\section{INTRODUÇÃO}

Para retratar a história política dos movimentos populares brasileiros na segunda metade do século passado, pode-se partir da análise de dois grandes conceitos: "libertação" e "hegemonia".

A "libertação" foi a tônica predominante nos anos 1960 e 1970. A "hegemonia" tem sido a palavra de ordem ao longo dos anos 1980 e 1990. A primeira, representada particularmente pelo pensamento de Paulo Freire, expressava os anseios e as lutas dos que queriam se libertar da ditadura (1964-1984) e da história de colonialismo imposto ao Brasil. A segunda, tendo Antonio Gramsci como referência, passou a significar o projeto das forças populares que com o fim da ditadura orientavam seus esforços para a construção de uma democracia social e para a conquista da direção política.

As duas, entre os anos 1960 e 1990, foram se entrelaçando e acabaram influenciando fortemente movimentos sociais, organizações políticas e educadores populares brasileiros, imprimindo uma unidade de fundo às suas práticas político-pedagógicas e conferindo uma sintonia peculiar de linguagem, de formulações teóricas e de projetos sociopolíticos.
A partir dos anos 1990, no entanto, intensas mudanças na política, na economia e na cultura vêm provocando uma ressignificação dos paradigmas de "libertação" e "hegemonia", sinalizando um novo ciclo da história das lutas populares. Nas páginas que se seguem, queremos mostrar como Paulo Freire (1921-1997) e Antonio Gramsci (1891-1937) aparecem juntos não apenas nas datas comemorativas de nascimento e morte, mas continuam associados na inspiração das atuais lutas dos "oprimidos" e dos "subalternos" do Brasil e do mundo.

\section{A LIBERTAÇÃO}

\section{II.1. A busca da própria identidade}

Não foi por acaso que o conceito de "libertação" veio a permear progressivamente o ideário e as atividades políticas de diversos segmentos sociais durante a ditadura militar (1964-1984). Esta, de fato, tornara-se a expressão mais palpável do que havia sido em grande parte a história do Brasil.

Mais uma vez, de fora e pelo alto, um modelo arbitrário de sociedade era imposto ao Brasil, sufocando com brutalidade a maior mobilização popular de sua história. A repressão que se seguiu ao 
golpe de 1964 desmantelou e dispersou organizações políticas, mobilizações estudantis, sindicatos dos trabalhadores, movimentos sociais, círculos de cultura e toda a efervescência política que entre final de 50 e início de 60 vinha "conscientizando" e organizando crescentes segmentos da sociedade brasileira (SEMERARO, 1994, p. 23-33).

Portanto, na segunda metade dos anos 1960, quando no Brasil se levanta o apelo à "libertação", não se tratava apenas de uma reação imediata à ditadura. Seu grito se estendia contra todas as versões de "Casa grande e senzala", aqui implantadas pelas sucessivas invasões e pelas diversas formas que a dominação veio assumindo no tempo com as capitanias hereditárias, as oligarquias fundiárias, a aristocracia industrial, as corporações transnacionais e as diversas ditaduras militares, políticas e culturais.

Mas, diversamente dos numerosos e desarticulados levantes libertários que nunca haviam deixado de existir ao longo de sua história, as mobilizações que "sacudiram" o Brasil antes de 1964 apresentavam condições mais favoráveis para mudar os rumos do país. Suas intensas atividades não apenas desvendavam as contradições estruturais e faziam compreender as raízes profundas da dominação, mas com sua força organizativa e suas articulações políticas esboçavam um projeto alternativo de sociedade.

Junto com as manifestações de resistência, de fato, vinha se delineando um processo de "libertação" que visava a se livrar da coerção militar e das ingerências externas nela implícitas, mas também do dominador invisível veiculado pela ideologia dominante e alojado nas relações sociais (FREIRE, 1980, p. 58-61; 1992, p. 56). Paradoxalmente, portanto, o autoritarismo acabou incentivando a valorização das raízes populares, a "educação para a autonomia", a luta contra as diversas formas de dominação disseminadas nas desigualdades, no preconceito, no racismo, no machismo, na educação, na linguagem, na cultura. Aos poucos, como Paulo Freire relata, a educação popular foi se tornando "ato político": "Houve um momento na minha vida de educador em que eu não falava sobre política e educação. Foi meu momento mais ingênuo. Houve outro momento em que comecei a falar sobre os aspectos políti$\cos$ da educação. Esse foi o momento menos ingênuo, quando escrevi a Pedagogia do oprimido.
No segundo momento, entretanto, eu ainda pensava que a educação não era política, mas que só tinha um aspecto político. Hoje, no terceiro momento, para mim, a educação é política. Hoje, digo que a educação tem a qualidade de ser política, o que modela o processo de aprendizagem. A educação é política e a política tem educabilidade" (FREIRE \& SHOR, 1987, p. 75-76).

Nesses anos, na medida em que se tomava cada vez mais consciência da magnitude da dominação e das imensas carências do Brasil e se percebia que não se tratava de aspectos circunstanciais mas de um fenômeno sistemático e estrutural, o papel dos intelectuais e dos educadores passou a ser profundamente questionado. Postos diante de problemas tão dramáticos, muitos destes se associaram às lutas populares e acabaram redirecionando seus estudos e pesquisas. Tornava-se cada vez mais claro que a educação não podia deixar de ser "ato político" e que "é tão impossível negar a natureza política do processo educativo quanto negar o caráter educativo do ato político" (FREIRE, 1982, p. 23).

Não é de se admirar, portanto, se, em plena ditadura, assistimos a um florescimento espantoso de práticas político-pedagógicas inovadoras e de criações teóricas em diversos campos que tiveram na "libertação" sua temática aglutinadora. Sem que houvesse um "centro" organizador ou um único pólo de irradiação, entre o final dos anos 1960 e início de 1970, ocorre uma convergência de idéias e uma simultaneidade de inspirações em torno da nova episteme promovida pelo paradigma da libertação.

No espaço restrito deste artigo, limitamo-nos a mencionar só alguns escritos e eventos mais significativos:

1. em 1967, P. Freire publica Educação como prática da liberdade e, em seguida, Pedagogia do oprimido (1968). Particularmente nesse livro, apresenta a grande virada na concepção de educação ao fazer do "oprimido" um surpreendente ator político detentor de um revolucionário método pedagógico;

2. em 1967, sai Dependencia, cambio social y urbanización latinoamericana, um texto fundamental de A. Quijano sobre a "teoria da dependência". Outros escritos seguem-se nessa mesma linha, tal como o de F. H. Car- 
doso e E. Faletto, Dependencia y desarrollo en América Latina (1967), e o de Teotônio dos Santos, Crise de la teoria del desarrollo y las relaciones de dependencia en América Latina (1969);

3. em 1968, A. Salazar Bondy publica o livro Existe una filosofia de nuestra América?, questionando a importação e a imitação mecânica da filosofia européia pelos latino-americanos. Em contraposição ao espírito de submissão e de dependência disseminado na América Latina, aponta a saída para uma "consciência libertadora";

4. em 1968, em Medellín, a II Conferência do Episcopado da América Latina (Cepal) oficializa a "opção pelos pobres", entendidos no sentido mais concreto de explorados econômica e socialmente, e condena abertamente o sistema capitalista;

5. nesse mesmo ano de 1968, G. Gutierrez escreve o artigo "Rumo a uma teologia da libertação", no qual começa a reinterpretar a tradição do pensamento cristão à luz das condições materiais de vida do povo latinoamericano e lança as bases de seu livro mais conhecido, Teologia da libertação (1970), seminal para inúmeros cristãos e teólogos que se engajam ao lado dos "oprimidos";

6. entre os diversos eventos de grande irradiação da temática da "libertação" nesse período na América Latina, aqui lembramos apenas: a) o II Congresso Nacional de Filosofia, Buenos Aires, 1970 e b) o I Encontro continental dos "cristãos para o socialismo", Santiago del Chile, 1972.

Salta aos olhos de todos o fato de que nesse período o marxismo de coloração latino-americana e o cristianismo renovado pelo Concílio Vaticano II confluem para a elaboração da concepção de libertação que vinha fermentando nos diversos movimentos políticos populares brasileiros e latino-americanos.

Em uma operação inédita e ousada de interlocução entre esquerda latino-americana e igreja popular - duas formas "heréticas" de política e de religião -, começava a fermentar uma nova concepção de mundo que questionava não apenas os velhos modelos de partidos e de Igreja, mas que se constituía principalmente como uma gran- de ameaça e uma alternativa para todo o sistema da violência capitalista e todo tipo de organizações autoritárias.

A repercussão e a força que esse movimento foi assumindo levaram alguns analistas a falar de um fenômeno histórico comparável com a Reforma Protestante ocorrida na Europa no século XVI (ASSMANN, 1974, p. 199) e a relacioná-lo com a formação da filosofia da práxis que, no século XIX, se delineou a partir de uma síntese original das correntes mais avançadas na política, na economia e na filosofia (GUTIERREZ, 1981, p. 296).

O entrelaçamento das aspirações libertárias com o ideário marxista mostrava como o Brasil e o Terceiro Mundo, em sua chocante situação de desumanização, eram o resultado histórico da violência perpetrada pela "civilização ocidental" e pela exploração capitalista, não um fenômeno natural, fruto do atraso e da inferioridade inerentes a seus habitantes. Como Marx havia já apontado, parecia realmente claro que é nas colônias que a profunda hipocrisia, a barbárie intrínseca da civilização burguesa se manifestam mais abertamente (MARX, 1998, p. 863-874).

Tornava-se evidente que, no período de longa dominação por que passaram, o Brasil e os países latino-americanos haviam sido transformados em "associados e dependentes". E que as teorias que defendiam o desenvolvimento nos moldes capitalistas ignoravam que o subdesenvolvimento era principalmente o subproduto das políticas econômicas e comerciais impostas pelos países centrais. Portanto, essa condição de dependência nunca iria ser vencida pela implantação de processos de modernização e pela imitação dos modelos dos dominadores. Se a pobreza e o atraso dos países latino-americanos eram funcionais à riqueza dos países centrais, a ideologia "desenvolvimentista", por trás de suas aparências humanitárias, só reproduzia e aprofundava as desigualdades, fortalecendo assim o próprio sistema capitalista.

\section{II.2. O novo ponto de partida}

Mas, ao mesmo tempo que elaboravam críticas radicais e contundentes ao capitalismo, as teorias da libertação apontavam para um novo ponto de partida. Indicavam no próprio "oprimido" o sujeito para superar a opressão. Mostravam que as transformações e a revolução dependiam substancialmente de sua capacidade de tornar-se protagonista de sua própria história. 
Mais do que o "trabalhador" e o "proletariado" - classes sociais consideradas a partir das fábricas e das cidades industrializadas -, as reflexões que foram surgindo em torno do conceito de "oprimido" evocavam toda a carga de "desumanização" e de "alienação" geradas pelo capitalismo no devassado território do Terceiro Mundo. Neste, emergia não apenas a "mais-valia" extraída das mãos do operário, mas eram desmascarados os imensos campos de trabalho forçado em que haviam sido transformadas regiões inteiras do planeta. As seqüelas dessa moderna escravidão eram visíveis não só no saque e na transferência gigantesca de riquezas, mas principalmente nas altas taxas de mortalidade infantil, no analfabetismo invencível, nos mocambos, na explosão das favelas, na violência urbana, na mão-de-obra barata, na interdição do conhecimento científico e tecnológico.

Do recinto das fábricas e das lutas partidárias, as reflexões em torno do "oprimido" faziam levantar o olhar para as imensas regiões do planeta onde as desigualdades, as injustiças, os horrores da exploração atingiam mais de $2 / 3$ da população mundial. É exatamente nos anos 1960 e 1970 que explode no mundo inteiro a onda de reflexões sobre o desastre do assim chamado Terceiro Mundo. Para além da relação patrão-operário ou da linha Leste-Oeste, a visão se estendia agora para um outro grande eixo: a relação de desigualdade entre Norte e Sul, entre países centrais e regiões periféricas. O que emergia dessa visão não eram abstratos "cidadãos" nem macrossujeitos como o "povo" e a "nação", mas eram seres humanos muito concretos. Eram os "esfarrapados", aos quais Freire dedicava a Pedagogia do oprimido, eram os "que conhecemos em nossas experiências educativas, esses homens, mulheres, meninos desesperançados, mortos em vida, sobras de gente" (FREIRE, 1970, p. 29). Eram os "condenados da terra", a "subespécie", os submersos com os quais muitos educadores, intelectuais, religiosos e políticos passavam a compartilhar a condição de vida e cujas dores assumiam.

O favelado, o negro, a empregada doméstica, o bóia-fria, o índio, o "peão", o professor/leigo, o sem-terra, o sem-teto, o mestiço saíam da sombra e entravam nas análises sociais e das pesquisas acadêmicas, mostrando as tantas faces desfiguradas do trabalhador nas colônias. Ampliavase, assim, o conceito de classe e se refaziam as contas da espantosa "mais-valia" mundialmente acumulada. O "oprimido", além da mão-de-obra barata, evocava a invasão, o genocídio, o comércio dos escravos, a desapropriação, o apartheid, o preconceito, a tortura, a migração, o exílio. Começava a ser narrada a história dos horrores do capitalismo nos países colonizados, até então ocultada e naturalizada. $\mathrm{O}$ que se descobria no Terceiro Mundo não era só o operário que ainda podia contar com alguma organização ou a proteção de uma certa legislação, mas o ser humano sem história, totalmente vulnerável, sem nenhuma importância, espoliado, destituído dos direitos mais elementares de vida, destinado a desaparecer sem deixar rastro. O "oprimido" - como o analisa Enrique Dussel - era o "sujeito negado", o sujeitado, a "vítima que não pode viver" (2002, p. 520).

E, paradoxalmente, esse "ser anulado" era visto como novo ponto de partida, como um novo sujeito capaz de construir um outro mundo. Tratava-se, portanto, de lutar não apenas por melhores condições de trabalho, pela ordem e pelo progresso, mas por um outro projeto de civilização. $\mathrm{O}$ resgate da própria vida e da dignidade da humanidade não dependia então só de disciplina econômica, de ajustes e modernização. Era necessário que "o outro", desfigurado em sua humanidade pelo sistema de apartheid instituído pela "comunidade dos senhores" e pelo círculo fechado dos "povos livres" (LOSURDO, 2006, p. 212-216) aprendesse a se libertar da opressão com as próprias mãos e a mostrar que para alcançar a liberdade e a prosperidade não há necessidade de escravizar os outros.

Sem cair na comiseração e em sentimentos de vitimismo, era necessário aprender a construir o próprio projeto de vida, a narrar a própria história e a afirmar a própria "alteridade". Sem recorrer à violência como fazia o opressor, era preciso promover a conscientização e as organizações que podiam socializar a riqueza e o poder. Portanto, o marginalizado nas periferias não devia ser objeto de piedade e de caridade, mas reconhecido como sujeito capaz de se resgatar e libertar o próprio mundo de sua história de alienação (LÖWY, 1991, p. 95-97).

Pela aproximação entre cristãos progressistas e marxistas, era possível ver como "libertação" e "oprimido" traziam a forte carga que derivava dos conceitos de "pobre" e de "explorado". O primeiro remetia a um referencial bíblico-cristão funda- 
mental e o segundo expressava a condição do trabalhador no sistema capitalista desvendado pelo marxismo. Os dois, cada um a seu modo, contribuíam na construção da proposta de "libertação" tanto com suas aspirações redentoras como por seu ímpeto revolucionário. Nas reflexões e nas práticas das organizações populares libertadoras desse período, portanto, ocorria um entrelaçamento que resultava em fórmulas como "socialismo cristão", "marxismo fenomenológico", "existencialismo revolucionário", tentativas de síntese que procuravam amalgamar espírito de comunidade e autoconsciência com as análises econômicas e a intervenção política apontadas pelas teorias marxistas.

\section{A CONSTRUÇÃO DA HEGEMONIA}

\section{III.1. A insuficiência da libertação}

Como se sabe, a práxis libertadora e as crescentes pressões de movimentos populares juntamente com outras forças sociopolíticas concorreram para minar e derrubar o regime militar. No início dos anos 1980, de fato, encerrava-se no Brasil um ciclo histórico e com ele se esgotavam também muitas concepções e práticas políticopedagógicas originadas em seu seio.

O próprio Freire já sinalizava o perigo de permanecer só nos horizontes da conscientização: "Assim como o ciclo gnosiológico não termina na etapa da aquisição do conhecimento já existente, pois que se prolonga até a fase da criação do novo conhecimento, a conscientização não pode parar na etapa do desvelamento da realidade. Sua autenticidade se dá quando a prática do desvelamento da realidade constitui uma unidade dinâmica e dialética com a prática da transformação da realidade" (1992, p. 103). Os círculos de cultura, "as comunidades de base", as práticas educacionais e as associações populares de bairro surgidas durante a ditadura haviam cumprido seu papel de resistência e de reivindicações.

Estava na hora de sair do casulo das associações-comunidades, das posições defensivas e periféricas. A crítica e a contraposição ao Estado autoritário e ao sistema capitalista não eram mais suficientes. Era preciso avançar em direção à elaboração de propostas alternativas, desenvolver a capacidade de constituir novas organizações políticas na sociedade civil, conquistar espaços suficientes para preparar a formação de um Estado democrático-popular. Por isso, nos anos 80 repe- tia-se que não era suficiente "libertar-se da" opressão e contentar-se com a liberdade negativa. Era necessário desenvolver a liberdade positiva, "libertar-se para" reconstruir a sociedade, democratizar direitos e assumir a direção política: "a mobilização, que implica a organização para a luta, é algo fundamental à conscientização, é algo mais profundo que uma pura tomada de consciência" (FREIRE \& SHOR, 1986, p. 115). Em suma, além de romper com o passado colonial e alcançar a autonomia, precisava se preparar para criar, controlar e conduzir o complexo processo da nova formação político-partidária e das instituições democráticas necessárias para o país.

Nos anos de resistência, apesar de tudo, o oprimido havia gerado um processo de libertação, lançando as premissas para passar da condição de "subjugação" à de "subjetivação". Um fenômeno parecido é delineado por Gramsci quando descreve o processo da "catarse": a transformação do indivíduo passivo e dominado pelas estruturas econômicas em sujeito ativo e socializado capaz de tomar iniciativa e se impor com um projeto próprio de sociedade. "O amadurecimento do momento "catártico" - observava o autor dos Cadernos do cárcere - torna-se o ponto de partida para toda a filosofia da práxis" (Q 10, $\S 6, \mathrm{p}$. 1244,). E a "catarse da libertação" no Brasil daqueles anos, poderíamos dizer, promoveu não apenas a "consciência das contradições" do sistema capitalista e a transformação das relações intersubjetivas, mas, para voltarmos às palavras de Gramsci, criava as premissas para tornar-se "a expressão das classes subalternas que desejam educar-se a si mesmas na arte de governar" (Q 10, § 41, p. 1320,).

Além de se "libertar" era necessário, portanto, conquistar a "hegemonia". Para chegar a isso não era suficiente se contrapor e derrubar o Estado autoritário, era preciso conquistar espaços na complexa rede da sociedade civil e se organizar como sociedade política. Era urgente ganhar o consenso ativo da população no imenso campo da cultura, na elaboração da ideologia, nas organizações sociais, na formação de partidos, na orientação da produção, na condução da economia e da administração pública. Percebia-se, de fato, que as classes dominantes eram hegemônicas porque além do domínio na esfera econômica possuíam o controle de setores estratégicos como a mídia e a produção do conhecimento. Era o que as análises de Gramsci mostravam quando alertava que, nos 
países "ocidentais", “o Estado era apenas uma trincheira avançada por trás da qual existia uma sólida cadeia de fortalezas e casamatas" constituída pelo complexo sistema de organizações da sociedade civil (Q13, § 7, p. 1567). E, aqui, de fato, encontrava-se a linha de defesa mais sólida da burguesia no Brasil.

Entende-se por que entre o final dos anos 1970 e início dos anos 1980 começam a se popularizar conceitos provenientes do vocabulário de Gramsci tanto na política e no mundo acadêmico como nos movimentos populares. "A leitura crítica da realidade - alertava atentamente P. Freire -, associada a certas práticas claramente políticas de mobilização e organização, pode constituir-se num instrumento para o que Gramsci chama de ação contra-hegemônica" (1982, p. 21) e, em seguida, emendava: "Para mim o caminho gramsciano é fascinante. É nessa perspectiva que me coloco" (FREIRE, GADOTTI \& GUIMARÃES, 1986, p. 68). Não exagera, portanto, Glória M. Gohn quando observa que "Gramsci é o autor que mais contribuiu para as análises e as dinâmicas das lutas e dos movimentos populares urbanos na América Latina nos anos [19]70 e [19]80" (1997, p. 188).

Assim, aos poucos, a mística e a "radicalidade utópica" provenientes da paixão "libertadora" passaram a dar lugar mais ao "realismo político" e à racionalidade estratégica de organizações sociais e partidárias. E Gramsci simbolizava perfeitamente essa luta: era o "oprimido" que havia vencido o fascismo na prisão e havia apontado em seus escritos os caminhos para a conquista da hegemonia das classes populares nas complexas sociedades contemporâneas.

Entre outras reflexões, a importância de Gramsci consistia no fato de que havia analisado como poucos a fenomenologia do poder e a construção do partido moderno para chegar à hegemonia. Havia mostrado que a revolução não ocorria apenas com a tomada do aparelho estatal $\mathrm{e} o$ ataque frontal às classes dominantes. $E$, neste sentido, os "movimentos" da "libertação", fundamentalmente, apresentavam-se ainda com uma certa dose de "romantismo" ao combater de fora o sistema existente. Precisava, agora, entrar no mesmo terreno da burguesia para conhecer por dentro os complexos mecanismos institucionais que fazem funcionar um país, para ter acesso ao sistema financeiro, à mídia, ao conhecimento científico e à tecnologia mais avançada. Mais do que a "de movimento", precisava valorizar a "guerra de posição", quer dizer, desenvolver a formação para uma política especializada, para criar organizações que pudessem aglutinar forças e preparar enfrentamentos sofisticados com os grupos dominantes afirmados há séculos no poder. Precisava passar do âmbito da "comunidade" para o de "partido", sair da visão periférica para alcançar a visão de totalidade, superar a vida de sobrevivência para pensar na produção de massa.

Gramsci, de fato, havia percebido que a perpetuação da burguesia no poder, mais do que pela violência, ocorria pela capacidade de ser "orgânica" aos centros vitais de um país e pelo consenso que, embora passivo, sabia criar nas massas. Daí, para Gramsci, a necessidade de elaborar "uma teoria da hegemonia como complemento da teoria do Estado-força e como forma atual da doutrina da revolução permanente" (Q 10, §12, p. 1235). Parafraseando Gramsci, quando analisa o período posterior ao ano de 1870 na Europa, onde mostra que " $[\ldots]$ as relações organizacionais internas e internacionais do Estado se tornam mais complexas e sólidas, e a fórmula de 1848 de 'revolução permanente' é superada na ciência política com a fórmula de "hegemonia civil'” (Q 13, § 7, p. 1566), poder-se-ia dizer que também no Brasil depois de 1984 as formulações referenciadas na "libertação" deixam de ter sua força aglutinadora, enquanto ganha impulso a concentração de forças para a conquista da "hegemonia" na árdua construção da democracia social. No lugar de pensar a política só como ímpeto libertador, precisava pensá-la como se realizando no mesmo campo da burguesia, como sendo um "assédio recíproco", uma "guerra de posição". E Gramsci apontava exatamente que "a guerra de posição, na política, é o conceito de hegemonia, que pode nascer só depois de algumas premissas, ou seja: as grandes organizações populares de tipo moderno" (Q 8, § 52, p. 972-973).

Quando começa a se colocar no centro da práxis político-pedagógica o projeto de hegemonia, além de formar pessoas críticas, "libertas" e éticas, incentiva-se a desencadear "o movimento real que supera o estado atual das coisas" (MARX \& ENGELS, 1998, p. 32) e preparar "dirigentes". Mais do que preocupada em se livrar da dominação e resgatar a própria dignidade, a conquista da hegemonia mobiliza para construir um projeto alternativo de sociedade, para se habilitar na direção de processos políticos e culturais capazes de 
expandir para toda a sociedade a democracia popular.

Esse deslocamento é particularmente visível na mudança de foco que ocorre nas práticas político-pedagógicas, nas elaborações teóricas e na linguagem das organizações populares. Nesse período, nota-se um entrelaçamento e depois um progressivo deslizamento de vocabulário que vai da "opressão" para a "hegemonia", da "libertação" para a "direção", da "identidade" para o "projeto", de "movimentos" para "partidos", de "povo" para "classe", de "diálogo" para "poder", de "mística" para "estratégia".

\section{III.2. A difícil construção da hegemonia}

Em 1984, de fato, ampliava-se no Brasil não apenas o espaço da "sociedade civil", mas reabria-se principalmente o campo de atuação no âmbito da "sociedade política". Duas esferas que, para Gramsci, faziam parte da "superestrutura", cuja importância precisava aprender a valorizar em contrapeso à infra-estrutura econômica e ao "desenvolvimentismo" promovidos no período da ditadura militar. Embora distintas, as duas mantinham uma estreita relação e constituíam o complexo sistema do Estado moderno (Q 6, § 88, p. 764).

Dos escritos de Gramsci, portanto, aprendiase que o Estado não podia ser entendido apenas como "sociedade política (ou ditadura ou aparato de coerção)". Na verdade, no "ocidente" o Estado apresentava-se como "um equilíbrio entre sociedade política e sociedade civil", cuja hegemonia era exercida por meio de organizações consideradas privadas, como a igreja, os sindicatos, as escolas, as organizações de cultura etc (Q 25, § 4, p. 2287). Inspirado em Hegel e Lênin, Gramsci resgatava as dimensões ético-políticas do Estado e destacava o momento da hegemonia como essencial na concepção do Estado (Q 7, § 33, p. 881-882).

Sim, no Brasil as idéias de "libertação" haviam fermentado nos movimentos, na igreja, nos sindicatos, nas periferias, no campo, na educação e na cultura popular. Mas ainda não haviam enfrentado o problema do Estado e, conseqüentemente, da organização da "sociedade política" e da conquista da hegemonia na "sociedade civil". Ao analisar a realidade "muito complexa" e contraditória na Europa de seu tempo, Gramsci oferecia indicações metodológicas para delinear uma história dos grupos subalternos fragmentados nas inúmeras lutas sociopolíticas e observava que "as classes subalternas, por definição, não são unificadas e não podem se unificar até se tornarem 'Estado"” (Q 25, § 4, p. 2288-2289). Era o que começavam a perceber alguns movimentos populares brasileiros no novo contexto histórico pós-ditadura militar: embora houvesse muita euforia democrática, corriam o risco da pulverização e da dispersão.

Portanto, se as classes populares até então haviam encontrado sua aglutinação no combate ao Estado autoritário, o desafio agora consistia em se articular para criar um Estado democrático. E este não se construía apenas nas lutas parlamentares em torno da elaboração da Constituição, mas principalmente nos embates pela conquista da hegemonia, pela direção político-cultural na complexa e contraditória trama da sociedade civil que vinha se ampliando no Brasil.

Ao longo dos anos 1980, portanto, viu-se logo que para enfrentar e superar a hegemonia burguesa a linha de confronto não era mais sociedade civil X Estado, mas, principalmente, a disputa entre projetos emanados da sociedade civil burguesa $\mathrm{X}$ os que fermentavam na sociedade civil popular. A burguesia, em conformidade com sua ideologia liberal, entendia a sociedade civil como esfera dos negócios econômicos e visava a separar a política da economia, o público do privado. As organizações populares, ao contrário, entendiam-na como espaço de socialização dos direitos e de expansão da participação política para formar os cidadãos na construção do público e do Estado democrático. A hegemonia que deve ser construída pelas classes populares - alertava Gramsci - "não é o instrumento de governo de grupos dominantes que procuram o consenso e impõem a hegemonia sobre as classes subalternas”. Essas, ao contrário, "têm interesse em conhecer todas as verdades, inclusive as desagradáveis" (Q 10, § 41, p. 1320) e buscam estabelecer uma "relação pedagógica" (Q 11§ 67, p. 1505; Q 13, § 36, p. 1635) entre os governantes e os governados, de tal modo que se possa superar a concepção de poder como dominação e possam ser dadas as condições para que todos venham a "tornar-se dirigentes". Não se tratava, portanto, de uma estratégia para tornar o poder vertical mais aceitável e humanizado, mas de novas relações sociais, de um novo modo de entender a política, de um novo modo de organizar a produção, cujos objetivos eram a democra- 
tização efetiva da sociedade, ou seja, a elevação intelectual e moral das massas, a passagem dessas da posição de dirigidos à condição de dirigentes $(\mathrm{Q} 8, \S 191$, p. 1056).

Diversas organizações populares se orientaram nessa direção e conseguiram realizar experiências inovadoras na política e na educação. No entanto, ao longo dessas últimas duas décadas, as preocupações eleitorais e a concentração nos partidos, a profissionalização da política e o dispêndio de energias na conquista do poder governamental acabaram esvaziando os espaços voltados para a mobilização popular e a construção da hegemonia nos diversos campos da cultura e da sociedade civil. As perspectivas desenhadas pela "libertação" foram sendo consideradas "utópicas" e vistas como uma transição para se chegar à etapa superior da política partidária e das vitórias eleitorais com as quais a hegemonia acabou sendo confundida e identificada. Em seguida, a parlamentarização da política e as preocupações administrativas foram cavando um abismo ainda maior em relação aos movimentos populares cada vez mais entregues a si mesmos. Em analogia com Max Weber quando descreve o desencantamento que ocorreu no processo de formação da racionalidade moderna, é possível dizer que as preocupações jurídico-administrativas e os "jogos" políticos "pelo alto" na história recente das esquerdas brasileiras foram se impondo em detrimento do projeto popular de sociedade, da força arrebatadora da revolução e da mística da militância. Ao resgatar o "romantismo" político e as raízes do comunismo indígena de J. C. Mariátegui, M. Löwy ressalta "a dimensão espiritual e ética do combate revolucionário: a fé ("mística"), a solidariedade, a indignação moral, o compromisso total ("heróico"), comportando o risco e o perigo para a própria vida" (LÖWY, 2006, p. 17). A especificidade da política e da educação socialista no Brasil, portanto, não pode voltar as costas e prescindir da riquíssima experiência de generosidade e de "encantamento" promovidos por sua práxis libertadora. Esta, mesmo envolta em seu "romantismo", havia feito a "opção" pelos "oprimidos" e manifestado a ruptura com a exploração do trabalho e a acumulação privada do capital.

Se este horizonte de interpretação tiver algum acerto, é possível dizer que as décadas de 1980 e 1990 têm sido um dos períodos mais intensos e contraditórios de aprendizado político e pedagógico no Brasil. Se, por um lado, organizações po- pulares tanto na sociedade civil como no âmbito da sociedade política se multiplicaram e diversificaram, por outro lado, não se deve esquecer que durante essas décadas as classes burguesas brasileiras conseguiram impor o neoliberalismo na economia, o pragmatismo na política e o pósmodernismo na cultura, quebrando muitas tentativas de construção da hegemonia popular e seduzindo diversos intelectuais.

Sem dúvida, as lutas para a conquista do poder governamental e as experiências administrativas têm valor inestimável na construção da hegemonia. Mas as ambigüidades ideológicas e as armadilhas nas quais as esquerdas se deixaram enredar ao longo desse processo, muitas vezes, têm levado ao abandono de valores delineados pela práxis libertadora, ao "esquecimento" de seus compromissos de classe, a uma compreensão redutiva do sentido da hegemonia apontada por Gramsci. Hoje, como este sugere particularmente nos "critérios metódicos" do Caderno 25, § 5, seria necessário promover um estudo crítico das tentativas realizadas pelas "forças inovadoras" que procuraram passar "de grupos subalternos a grupos dirigentes", com o intuito de "identificar as fases por meio das quais elas adquiriram a autonomia diante dos inimigos a serem vencidos e a adesão dos grupos que os ajudaram ativa e passivamente $[. .$.$] " a conquistar espaços de hegemonia$ e a "se unificar em Estado".

Mas essa é uma história para ser analisada em outro momento. Aqui, por enquanto, nos limitamos a mostrar como os paradigmas de "libertação" e "hegemonia", representados por P. Freire e A. Gramsci, desempenharam papel decisivo na elaboração de uma práxis político-pedagógica original no Brasil ao longo da segunda metade do século, promovendo conquistas consideráveis na democracia, na política e na educação.

Em 2007, quando se comemoram os dez anos da morte de Freire e os 70 do desaparecimento de Gramsci, sinalizamos apenas a inseparabilidade desses dois grandes educadores e militantes políticos nas lutas populares brasileiras em vista de sua "libertação" e "hegemonia".

Sem concluir, indicamos alguns pontos para possíveis desdobramentos de um processo político-pedagógico criativo que está longe de ter esgotado todas as suas potencialidades: 
1. A "libertação" e a "hegemonia" são paradigmas fundamentais não só para entender a história das idéias e o processo políticopedagógico da segunda metade do século XX no Brasil e na América Latina. As concepções que elas expressam continuam atuais e fecundas, porque os problemas diante dos quais surgiram persistem e se agravaram;

2. A osmose entre o pensamento de P. Freie e A. Gramsci representa uma das maiores contribuições para a educação e a fillosofia política brasileira e latino-americana. Eles não se excluem, pelo contrário, se complementam e se enriquecem;

3. No Brasil, a utilização de muitos conceitos de Gramsci e sua "tradutibilidade" não podem prescindir da filosofia, da economia, da teologia e da pedagogia da libertação aqui elaboradas;

4. Não se deve contrapor nem confundir "libertação" e "hegemonia", assim como não se deve contrapor Freire a Gramsci e viceversa. Os dois, profundamente entrelaçados, devem ter suas peculiaridades respeitadas e valorizadas: o primeiro porque aprofunda mais os horizontes da libertação, a utopia, os movimentos, a ética, a afetividade, o diálogo, a intersubjetividade, as relações pedagógicas, a pluralidade, a periferia, os "oprimidos"; o segundo, por dar maior ênfase à estratégia política, ao enfrentamento ideológico, à classe, à organização do partido, à dialética, à conquista da hegemonia, à formação de 'dirigentes', à criação do Estado democrático-popular;

5. A árdua conquista da hegemonia popular no Brasil passa pelo aprofundamento do processo de libertação e esta se completa na conquista da hegemonia. $\mathrm{O}$ entrelaçamento das duas evita a adoção de idéias mesquinhas de política e de partido e torna-se uma arma poderosa para superar a concepção de poder como dominação e entendê-lo como "relação pedagógica" entre pessoas livres e socializadas que rompem com o capitalismo, com as modernas formas de colonização, com o paradigma governante/governado, Norte/Sul, centro/periferia.

Giovanni Semeraro (gsemeraro@globo.com) é Doutor em Educação pela Universidade Federal do Rio de Janeiro (UFRJ), Professor de Filosofia da Educação da Universidade Federal Fluminense (UFF), pesquisador do Conselho Nacional de Desenvolvimento Científico e Tecnológico (CNPq) e coordenador do Núcleo de Estudos e Pesquisas em Filosofia Política e Educação da UFF (Nufipe).

\section{REFERÊNCIAS BIBLIOGRÁFICAS}

ASSMANN, H. 1974. Teologia della prassi di liberazione. Assisi : Cittadella.

BONDY, A. S. 1968. Existe una filosofia de nuestra América? México : Siglo XXI.

CARDOSO, F. H. \& FALETTO, E. 1967. Dependencia y desarrollo en América Latina. México : Siglo XXI.

DUSSEL, E. 2002. Ética da libertação na idade da globalização e da exclusão. Petrópolis : Vozes.

FREIRE, P. 1967. Educação como prática da liberdade. São Paulo : Cortez.

1970. Pedagogia do oprimido. Rio de Janeiro : Zahar
1980. Conscientização. São Paulo : Moraes.

1982. A importância do ato de ler. São Paulo : Cortez.

1992. Pedagogia da esperança. Rio de Janeiro : Zahar.

FREIRE, P. \& SHOR, I. 1987. Medo e ousadia : o cotidiano do professor. Rio de Janeiro : Paz e Terra.

FREIRE, P.; GADOTTI, M. \& GUIMARÃES, S. 1986. Pedagogia : diálogo e conflito. São Paulo : Cortez.

GOHN, M. G. 1997. Teorias dos movimentos sociais. Paradigmas clássicos e contemporâneos. São Paulo : Loyola. 
GUTIERREZ, G. 1972. Teologia de la Liberación. Salamanca : Sígueme.

1981. A força histórica dos pobres. Petrópolis : Vozes.

GRAMSCI, A. 1975. Quaderni del carcere. 4 v. Torino : Einaudi.

LOSURDO, D. 2005. Controstoria del liberalismo. Roma : Laterza.

LÖWY, M. 1991. Marxismo e Teologia da Libertação. São Paulo : Cortez.

2006. Introdução. In : MARIÁTEGUI,

J. C. Por um socialismo indo-americano. Rio de Janeiro : UFRJ.

MARX, K. 1998. O Capital. Rio de Janeiro : Civilização Brasileira.
MARX, K. \& ENGELS, F. 1998. A ideologia alemã. São Paulo : Martins Fontes.

QUIJANO, A. 1967. Dependencia, cambio social y urbanización latinoamericana. Revista Mexicana de Sociologia, Ciudad de México, n. 30, p. 505-510.

SANTOS, T. 1969. Crise de la teoria del desarrollo y las relaciones de dependencia en América Latina. Ciudad de México : Siglo XXI.

SEMERARO, G. 1994. A primavera dos anos 60. São Paulo : Loyola.

2001. Gramsci e a sociedade civil. $2^{\mathrm{a}} \mathrm{ed}$. Petrópolis : Vozes.

2006. Gramsci e os novos embates da filosofia da práxis. Aparecida : Idéias e Letras. 
FROM LIBERATION TO HEGEMONY: FREIRE AND GRAMSCI IN DEMOCRATIZATION PROCESSES IN BRAZIL

\section{Giovanni Semeraro}

The popular struggles that have been unleashed in Brazil from the 1960s until today can be characterized by two major paradigms: "liberation" and "hegemony". "Liberation" was the dominant theme throughout the 1960s and 1970s. "Hegemony" was the word of order throughout the 1980s and 1990s. The first, represented primarily by Paulo Freire, and the second, associated fundamentally with Antonio Gramsci, became inseparably linked in the designing of an alternative project for society. This article presents a critical analysis of their meanings on the occasion of the 10th anniversary of Freire's death and the 70th since Gramsci's passing. The following text, in addition to perusing the meanings, differences and interconnections between "liberation" and "hegemony" in their historical context, presents a reinterpretation of the two paradigms in the face of the political and cultural changes that are currently underway in Brazil and Latin America.

KEYWORDS: Paulo Freire; Antonio Gramsci; liberation; hegemony; politics. 
DE LA LIBÉRATION A L'HÉGÉMONIE: FREIRE ET GRAMSCI DANS LE PROCESSUS DE DÉMOCRATISATION DU BRÉSIL

\section{Giovanni Semeraro}

Les luttes populaires qui ont eu lieu au Brésil depuis les années 1960 jusqu'à nos jours peuvent être caractérisées au moyen de deux paradigmes: « libération » et « hégémonie ». La « libération » donna le ton des années 1960 et 1970. L'« hégémonie » fut le mot d'ordre au long des années 1980 et 1990. Le premier, réprésenté principalement par Paulo Freire, et le second, ayant chez Antonio Gramsci sa référence la plus importante, se sont croisés et sont devenus inséparables sur un dessin d'un projet alternatif de société. Cet article présente une analyse critique de leurs sens compte tenu des dix ans de la mort de Paulo Freire et des 70 ans de la mort de Gramsci. Parallèlement aux signifiés, le texte qui suit aussi les différences et l'entrecroisement de « libération » et d' " hégémonie » dans leur contexte hitorique et social, présente une réinterprétation des deux paradigmes face aux changements politiques et culturels actuellement en cours au Brésil et en Amérique Latine.

MOTS-CLÉS: Paulo Freire; Antonio Gramsci; libération; hégémonie; politique. 